\title{
KAJIAN KEMITRAAN PETANI PAPRIKA (capsicum annum) DALAM UPAYA PENINGKATAN PENDAPATAN PETANI (Studi Kasus pada Petani Paprika Desa Cibodas Kabupaten Bandung Barat)
}

\author{
Nur Syamsiyah \\ Program Studi Agribisnis Fakultas Pertanian UNPAD \\ Jl.Raya Jatinangor Km.21 Bandung 40600 \\ Email: nur.syamsiyah@unpad.ac.id
}

\begin{abstract}
ABSTRAK
Tujuan penulisan ini adalah mengkaji kemitraan usaha yang dilakukan petani paprika dengan Kostaman Fruits and Vegetables Suppliers dalam meningkatkan pendapatan petani paprika Desa Cibodas Kecamatan Lembang Kabupaten Bandung Barat. Pola kemitraan yang terjadi pola kemitraan dagang umum, petani paprika berada pada subsistem kegiatan produksi dan Kostaman Fruit and Vegetables Supplier pada subsistem pemasaran hasil produksi. Metode penelitian dilakukan dengan desain kualitatif dengan melakukan teknik studi kasus (case study). Keunggulan pola kemitraan kemitraan ini adalah peningkatan pendapatan bagi petani paprika dan Kostaman Fruits and Vegetables Suppliers, kendala dan manfaat dari kemitraan usaha, kendala teknis berkaitan dengan faktor cuaca yang tidak menentu. Manfaat yang diperoleh dari proses kemitraan bagi petani adalah jaminan harga dan pasar, peningkatan pendapatan. Kostaman Fruits and Vegetables Supplier memperoleh jaminan pasokan paprika sehingga mampu memenuhi permintaan konsumen. Pembagian marjin pada setiap pelaku kemitraan, Margin petani sebesar 40,52 \% dan margin Kostaman Fruits and Vegetables Supplier sebesar 59,48 \%. Kemitraan antara petani paprika dan Kostaman Fruits and Vegetables Supplier menguntungkan kedua belah pihak.
\end{abstract}

Kata kunci : Kemitraan, Paprika, Pendapatan

\begin{abstract}
The main objective of studies to analyse business partnership paprika farmers and Kostaman Fruits and Vegetables Suppliers in increasing the farmers incomes in Cibodas Village, Lembang West Java Regency. Types partnership general trade, paprika farmer in a place production subsystem and Kostaman Fruits and Vegetables Supplier in marketing product subsystem. This research design was qualitative and used case study research technique. The advantages of business partnership are increasing income for paprika farmers and Kostaman Fruit and Vegetables Suppliers, contraints and benefit of partnership, technical contraints be related to uncertainty weather. Benefit of partnership for paprika farmers, price and market assurance, increasing incomes. Kostaman Fruits and Vegetables Supplier acquiring quarantee paprika supply to able consumer demand. Distribution of margin on every offender partnership. Farmers margin 40,52 \% and Kostaman Fruits and Vegetables Supplier margin 59,48\%. The partnership between the paprika farmer and kostaman Fruits and Vegetables Supplier benefits both sides.
\end{abstract}

Keywords : Partnership, paprika, Farmer's Income

\section{PENDAHULUAN}

Indonesia merupakan negara agraris, dimana rata-rata penduduknya bermata pencaharian sebagai pelaku usahatani. Sebagai salah satu sektor kegiatan ekonomi yang dilakukan rata-rata penduduk Indonesia, keberadaan usahatani harus selalu didukung agar keberadaannya tetap ada, agar dapat diperluas sehingga dapat meningkatkan kesejahteraan para pelaku usahatani melalui peningkatan pendapatan. Salah satu subsektor yang dianggap cukup berperan bagi perekonomian Indonesia adalah hortikultura. Peranan dan kontribusi tanaman hortikultura cukup baik bagi pendapatan nasional, hal ini dapat dilihat pada data Produk Domestik Bruto (PDB) dari tahun 2008 hingga tahun 2011 mengalami peningkatan (sumber Direktorat Jenderal Hortikultura 2012). Paprika merupakan salah satu sayuran yang memiliki 
prospek yang cerah peluang pasar luar dan dalam negeri masih sangat terbuka.

Salah satu sentra produksi paprika adalah Provinsi Jawa Barat yaitu Bandung, Garut, Sukabumi, Cianjur dan Bogor. Pengembangan usahatani paprika potensial karena kondisi lahan dan iklim yang sesuai dengan syarat tumbuh tanaman paprika. Kabupaten Bandung Barat memiliki beberapa sentra produksi paprika, salah satunya adalah Desa Cibodas. Usahatani paprika di Desa Cibodas dilakukan dengan sistem kemitraan dengan Kostaman Fruits and Vegetables Supplier, diharapkan dengan sistem kemitraan yang dilakukan antara petani dengan supplier maka petani dan supplier dapat mengambil manfaatnya sehingga kerjasama yang terjalin adalah kerjasama yang saling menguntungkan dan bersama-sama dalam mengatasi kendala yang dihadapi baik faktor kualitas, kuantitas, kontinuitas, pemasaran dan permodalan. Sebelum adanya kemitraan petani tidak memiliki kepastian pasar dan harga, petani menjual produknya ke tengkulak.

Kostaman Fruits and Vegetables Supplier merupakan salah satu badan usaha agribisnis yang bergerak di bidang pemasaran hasil pertanian di Desa Cibodas. Atau dapat juga disebut sebagai rumah kemasan (packing house). Awalnya perusahaan tidak melakukan kemitraan hanya membeli pasokan paprika dari pedagang pengumpul atau pasar-pasar tradisional. Permintaan yang semakin tinggi membuat perusahaan harus mampu menjamin kualitas, kuantitas dan kontinuitas paprika sesuai dengan permintaan pasar. Penelitian ini bertujuan untuk: (1) mengidentifikasi pola kemitraan antara petani paprika dengan Kostaman Fruits and Vegetables Supplier; dan (2) mengidentifikasi kendala dan manfaat yang diperoleh dari kemitraan yang dilakukan antara petani paprika dan Kostaman Fruits and Vegetables Supplier.

\section{METODE PENELITIAN}

Desain penelitian adalah desain kualitatif, teknik penelitian yang digunakan adalah studi kasus (case study). penentuan lokasi penelitian ditentukan dengan sengaja didasarkan pada pertimbangan sebagai berikut: Desa Cibodas Merupakan salah satu sentra produksi paprika di Kabupaten Bandung Barat dan kostaman Fruits and Vegetables Supplier merupakan perusahaan agribisnis yang berkembang di wilayah Desa Cibodas Kecamatan Lembang Kabupaten Bandung Barat.
Jenis data primer yang diperlukan dalam penelitian ini adalah analisis usahatani paprika, data sekunder yang diperlukan adalah berupa pola kemitraan, informasi harga, hak dan kewajiban dalam kemitraan. Data sekunder diperoleh melalui studi pustaka, instansi terkait seperti : Kementrian Pertanian, Dirjen Hortikultura, Kementrian Perdagangan dan perindustrian dan lainnya.

Responden dalam penelitian ini ialah petani paprika di sentra produksi paprika Desa Cibodas Kecamatan Lembang Kabupaten Bandung Barat. Dan pihak perusahaan Kostaman Fruits and Vegetables Supplier. Teknik pengambilan data dilakukan melalui observasi, wawancara yang dilakukan terhadap petani paprika yang menjadi mitra perusahaan Kostaman Friuts and Vegetables Supplier. Penelitian ini menggunakan analisis kualitatif yang digunakan dalam menganalisis pola kemitraan yang dilakukan kedua belah pihak. Dimana kegiatan kemitraan dijabarkan secara deskriptif dan terperinci sehingga menggambarkan hak dan kewajiban masingmasing pihak yang bermitra, pembagian hasil, sanksi yang diberikan bagi pihak yang melanggar.

Kendala dan manfaat dianalisis

berdasarkan kendala aspek ekonomi, teknis maupun sosial baik di tingkat petani maupun perusahaan mitra selama melakukan kemitraan. Dalam bidang ekonomi peningkatan pendapatan dilihat dari perolehan margin rantai nilai pada setiap pelaku kemitraan. Langkah-langkah yang dilakukan dalam menganalisis biaya dan margin adalah sebagai berikut: (1) menghitung biayabiaya yang dikeluarkkan masing-masing pelaku kemitraan; (2) menghitung penerimaan per pelaku kemitraan. Penerimaan dihitung dengan mengalikan volume terjual (Q) dengan harga jual (P); (3) menghitung rasio keuangan yaitu: (a) pendapatan bersih (penerimaan dikurangi biaya tetap dan dikurangi biaya variabel); dan (b) margin bersih, yakni pendapatan bersih per produk, margin bersih dihitung dengan membagi pendapatan bersih pelaku dengan keseluruhan jumlah produk yang terjual (Q). Dam (4) posisi keuangan relatif para pelaku dalam rantai nilai. Tujuan dari langkah ini adalah mengambil simpulan tentang posisi keuangan antara lain pembagian biaya, penerimaan, pendapatan bersih (laba), dan margin antara para pelaku kemitraan dibandingkan dengan pelaku lainnya di dalam rantai. Cara yang dapat digunakan untuk menyajikan posisi keuangan para pelaku kemitraan adalah dalam bentuk tabel. 
Tabel 1. Perhitungan Margin Rantai Nilai Para Pelaku Kemitraan

\begin{tabular}{|c|c|c|c|c|}
\hline Pelaku & & Petani & Supplier & Total \\
\hline \multirow[t]{3}{*}{ Biaya } & Total & A & B & $\mathrm{C}=\mathrm{A}+\mathrm{B}$ \\
\hline & Biaya/kg & & & \\
\hline & $\begin{array}{l}\text { \% Biaya/ } \\
\mathrm{kg}\end{array}$ & $\mathrm{A} / \mathrm{C}$ & $\mathrm{B} / \mathrm{C}$ & 100 \\
\hline Revenue & Harga/kg & $\mathrm{D}$ & $\mathrm{E}$ & \\
\hline \multirow[t]{3}{*}{ Laba } & Laba/kg & D-A & E-B & $\mathrm{F}=(\mathrm{D}-\mathrm{A})$ \\
\hline & & & & $+(\mathrm{E}-\mathrm{B})$ \\
\hline & $\begin{array}{l}\text { \% Laba } \\
\text { Total }\end{array}$ & $(\mathrm{DA}) / \mathrm{F}$ & $(\mathrm{E}-\mathrm{B}) / \mathrm{F}$ & 100 \\
\hline \multirow{2}{*}{$\begin{array}{l}\text { Total } \\
\text { Margin }\end{array}$} & Margin/kg & $\mathrm{D}$ & E-D & $E$ \\
\hline & $\begin{array}{l}\text { \% Margin/ } \\
\mathrm{kg}\end{array}$ & $\mathrm{D} / \mathrm{E}$ & $(\mathrm{E}-\mathrm{D}) / \mathrm{E}$ & 100 \\
\hline
\end{tabular}

Sumber : ACIAR (2012)

Peningkatan pendapatan petani paprika diketahui dengan perbedaan pendapatan antara menjual keseluruhan jumlah produksinya ke pasar lokal dan menjual ke Kostaman Fruit and Vegetables Supplier dilihat dari margin pada rantai nilai.

\section{HASIL DAN PEMBAHASAN Pola Kemitraan Usaha}

Pola kemitraan yang terjalin antara petani paprika dengan Kostaman Fruits and Vegetables Suppliers adalah pola dagang umum, dimana petani berada pada subsistem produksi dan pihak perusahaan pada subsistem pemasaran hasil produksi. Petani diharapkan dapat fokus pada kegiatan produksi sehingga mampu meningkatkan produktivitas paprika yang dihasilkan. Perusahaan juga bertanggungjawab pada pengelolaan petani mitra sehingga mampu meningkatkan produksi dan pendapatan petani mitra.

Petani mitra dipilih perusahaan dengan menggunakan sampel produksi paprika dan komitmen petani terhadap kualitas, kuantitas dan kontinuitas paprika yang dihasilkan petani. Kualitas yang diinginkan perusahaan adalah grade $\mathrm{A}$ dan grade $\mathrm{B}$ dengan berat 1 ons -2 ons per buah. Penetapan harga disesuaikan dengan harga paprika di pasar, harga paprika tergantung dari warna. Paprika hijau dibeli dengan harga $\mathrm{Rp} 17.000$ per kg, paprika merah Rp 22.000 per kg, paprika kuning Rp 25.000 per kg dan paprika orange Rp 27.000 per kg.

Keberhasilan kemitraan yang dilakukan antara petani dengan perusahaan dapat dilihat dari kedua belah pihak dalam menjalankan aturanm hak dan kewajiban yang telah disepakati. Pihak yang terlibat secara langsung adalah Kostaman Fruits and Vegetables
Supplier sebagai perusahaan mitra dan petani paprika yang bermitra dengan Kostaman Fruits and Vegetables Supplier. Masing-masing pelaku menjalankan kegiatan yang berbedabeda.

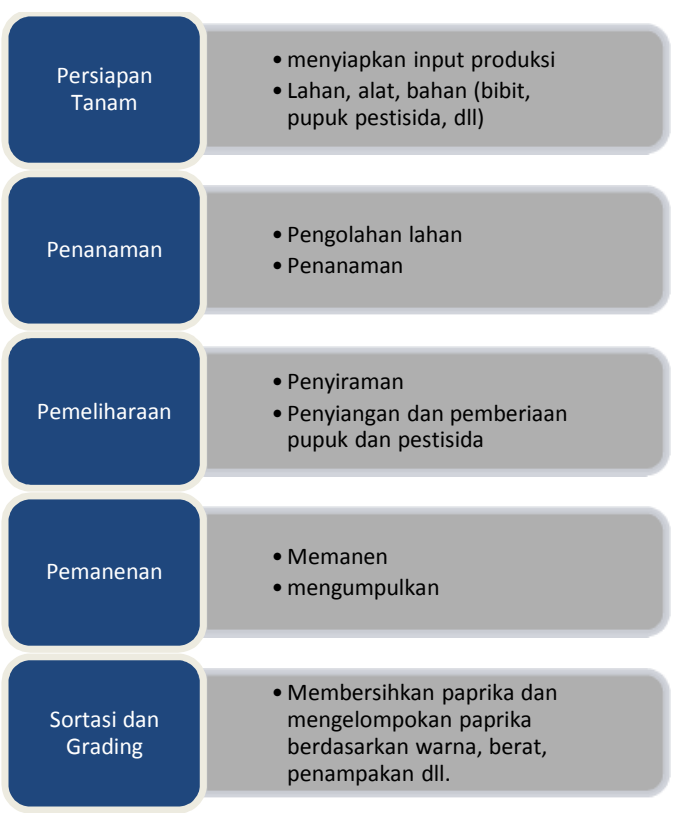

Gambar 1. Kegiatan Petani Paprika

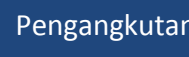

Gambar 2. Kegiatan Kostaman Fruits and Vegetables Supplier

Berdasarkan gambar di atas, dimana masing-masing pelalu memiliki hak dan kewajiban sebagai berikut: (1) hak petani mitra adalah mendapatkan jaminan pasar sesuai dengan harga yang telah ditetapkan dan menerima hasil penjualan tepat waktu dan tidak melewati masa jatuh tempo; (2) hak perusahaan adalah mendapatkan jaminan pasokan paprika, baik kualitas, kuantitas dan kontinuitas; (3) kewajiban petani mitra adalah melaksanakan budidaya paprika dengan benar, melaksanakan panen tepat waktu, dan menyerahkan hasil panen sesuai dengan kualitas dan kuantitas yang diinginkan perusahaan mitra; dan (4) kewajiban perusahaan mitra adalah membeli paprika hasil produksi petani dengan harga kesepakatan dan membayar hasil penjualan petani tepat waktu. 
Pelaksanaan kemitraan antara petani paprika dengan perusahaan mitra terjalin berdasarkan kekeluargaan. Tidak adanya kontrak kerja secara tertulis mengenai pembagian hasil, kualitas, kuantitas dan kontinuitas paprika semuanya bersifat lisan. Walopun demikian hingga saat ini kemitraan yang terjalin masih sangat baik karena masingmasing pihak melaksanakan hak dan kewajibannya dengan baik dan saling menjaga perasaan mitra kerjanya.

Pembagian hasil dilakukan berdasarkan kuantitas paprika yang dikirim petani, harga ditentukan berdasarkan kesepakatan sehingga tidak ada pihak yang dirugikan dalam kemitraan ini. Perusahaan dan petani mitra bersikap saling pengertian sehingga jika harga dipasar sedang tinggi maka perusahaan memberikan kenaikan harga paprika kepada petani dan ketika hasil produksi petani menurun karena serangan hama, perusahaan mitrapun mengerti. Proses pembayaran dilakukan perusahaan mitra menggunakan sistem tempo, pembayaran biasanya dilakukan setiap tanggal 5 dan 20 tiap bulannya. Selama melakukan kemitraan baik petani maupun perusahaan belum pernah ada yang melanggar kesepakatan yang telah dibuat.

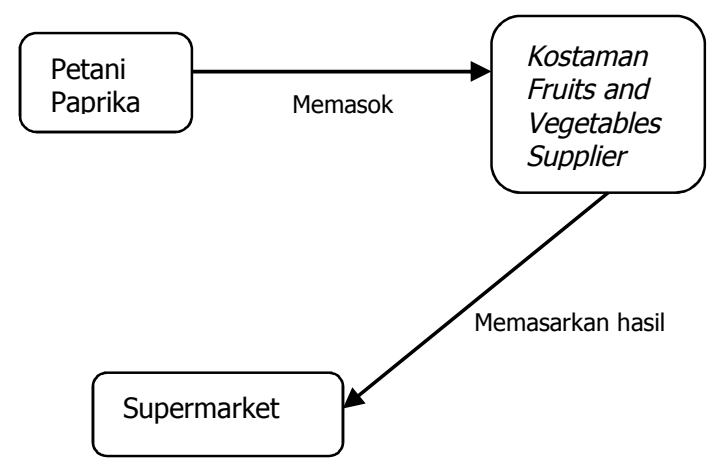

Gambar 3. Pola Kemitraan antara Petani Paprika dengan Kostaman Fruits and Vegetables Supplier

Petani paprika di Desa Cibodas

Kecamatan Lembang Kabupaten Bandung Barat mengetahui pasar tujuan untuk paprika yang dihasilkannya. Kostaman Fruits and Vegetables Supplier memasarkan parika yang dihasilkan petani ke 27 supermaket yaitu Sogo Plaza Indonesia, Sogo Pondok Indah Mall, Sogo Plaza Senayan, Sogo Senayan City, Sogo Mall Kelapa Gading, Sogo Grand Indonesia, Sogo Belleza Shopping, Sogo Kebun Jeruk, Sogo Cassablanca, Sogo Gardenia, Sogo Depok
Mall, Papaya Blok M, Papaya Bumi Mas, Kamome Blok M, Grand Lucky Sudirman, Grand Lucky Radio Dalam, Market City Pantai Indah Kapuk, Khemchik Pasific Palace Sudirman, Rezeki Swalayan Hayam Muruk, Total Buah Segar Kelapa Gading 1, Total Gading 1, Total Gading 2, Total Ampera, Total Fatmawati, Total Slipi, Total Karang Tengah, Total Alam Sutra.

\section{Kendala dan Manfaat Kemitraan Petani Paprika dengan Kostaman Fruits and Vegetables Supplier.}

Proses kemitraan terjadi bukan tanpa kendala, kendala yang terjadi dalam proses kemitraan yang terjalin antara petani paprika dengan Kostaman Fruits and Vegetables Supplier meliputi kendala teknis, ekonomi dan sosial. Pertama, kendala teknis di tingkat petani dan perusahaan berbeda karena kegiatan yang dilakukan oleh masing-masing pelaku kemitraan berbeda. Adapun kendala teknis yang dihadapi petani paprika adalah dalam menghasilkan paprika yang sesuai dengan kualitas, kuantitas dan kontinuitas yang diiinginkan perusahaan mitra. Kendala ini berkaitan dengan alam, karena budidaya paprika sangat tergantung oleh alam, walopun dibudidayakan di green house faktor cuaca masih sangat menentukan keberhasilan produksi paprika. Pada saat musin hujan paprika sangat mudah terserang busuk buah atau antracnose.

Kedua, kendala teknis yang dihadapi perusahaan berhubungan dengan pasokan paprika dari petani, jika pasokan menurun maka penjualan perusahaanpun akan menurun. Kendala lain adalah dalam proses pengangkutan hasil perusahaan belum memiliki alat transportasi dengan pendingin sehingga saat proses pengiriman beberapa paprika mengalami kerusakan; dan Ketiga, kendala ekonomi biasanya dialami perusahaan dalam menerima hasil penjualan dari supermarket, namun agar proses kemitraan berjalan dengan baik, perusahaan tetap memberikan kepada petani sesuai dengan masa jatuh temponya. Kendala ekonomi yang dialami perusahaan ini biasanya diatasi dengan menghentikan sementara pasokan kepasa supermaket yang mengalami keterlambatan pembayaran dan pasokan kembali akan dipenuhi ketika supermaket tersebut telah melakukan pembayaran.

Kendala dalam aspek sosial ini dialami oleh perusahaan dimana perusahaan hanya akan 
menerima paprika sesuai dengan grade yang telah ditentukan perusahaan, grade yang tidak sesuai akan dikembalikan kepada petani, petani kadang menjual paprika yang tidak sesuai dengan permintaan perusahaan ke pasar tradisional. Pada saat harga tinggi petani banyak yang menjual produknya ke pasar, namun perusahaan tidak melarang selama pasokan untuk perusahaan masih terpenuhi. Perusahaan tidak hanya mementingkan keuntungan perusahaannya saja, namun memikirkan pula petani mitranya.

\section{Manfaat Kemitraan Petani Paprika dengan Kostaman Fruits and Vegetables Supplier.}

Kemitraan merupakan salah satu bentuk kerjasama dengan memperhatikan prinsip saling memerlukan, saling memperkuat dan saling menguntungkan. Kata saling dimaknai bahwa dalam proses kemitraan masing-masing pelaku mendapatkan manfaat bagi setiap pelaku. Manfaat proses kemitraan yang terjalin antara petani paprika dengan Kostaman Fruits and Vegetables Supplier adalah sebagai berikut: Pertama, manfaat bagi petani, seperti: adanya kepastian pasar dan harga, penerimaan dan pendapatan relatif stabil, peningkatan kemampuan petani dalam memproduksi paprika, dan pengembangan skala usaha.

Kedua, manfaat bagi Kostaman Fruits and Vegetables Supplier, seperti: terjaminnya Pasokan paprika, mendapatkan pasokan dengan kualitas, kuantitas dan kontinuitas yang dibutuhkan perusahaan, penerimaan dan pendapatan perusahaan relatif stabil dan pengembangan skala usaha tidak hanya dikembangkan petani, perusahaan juga mengembangkan skala usaha melalui volume penjualan dan jenis produk yang dihasilkan petani yang memiliki produktivitas yang tinggi dan terus meningkat dari tahun-tahun sebelumnya.

\section{Margin Rantai Nilai Pada Pelaku Kemitraan} Petani dan Kostaman Fruits and

Vegetables Supplier menanggung biaya masing-masing sesuai dengan kegiatan yang dilakukannya (Tabel 3).

Berdasarkan perhitungan biaya produksi, penerimaan dan pendapatan masing-masing pelaku mitra memperoleh keuntungan berdasarkan margin yang diterima disajikan pada Tabel 4.
Tabel 3. Tanggungan Biaya Pelaku Kemitraan

\begin{tabular}{ll}
\hline Petani Paprika & $\begin{array}{l}\text { Kostaman Fruits and } \\
\text { Vegetables Supplier }\end{array}$ \\
\hline Biaya Tetap & Biaya Tetap \\
\hline - Bambu & - Timbangan \\
- Plastik UV & - Tenaga kerja \\
- Polybag & - Alat pengepakan. \\
- Plastik Mulsa & - transportasi \\
- Polynet & - Pajak \\
- Benang Kasar & - Listrik \\
- Paku & - Service transportation \\
- Kawat Tali & - Container \\
- Pompa Listrik & \\
- Instalasi pembuatan & \\
greenhouse & \\
- Pajak Bumi & \\
- Listrik & \\
\hline Biaya Variabel & Biaya Variabel \\
\hline - Benih & - Plastik pengemasan \\
- Nutrisi & - Streoform \\
- Arang Sekam & - Isolasi Bening. \\
- Pestisida & - Resiko kerusakan \\
- Tenaga Kerja & Paroduk \\
\hline
\end{tabular}

Tabel 4. Posisi Keuangan Relatif Para Pelaku Kemitraan

\begin{tabular}{llll}
\hline \multicolumn{1}{c}{$\begin{array}{c}\text { Pelaku dalam } \\
\text { Rantai Nilai }\end{array}$} & \multicolumn{1}{c}{ Petani } & \multicolumn{1}{c}{ Supplier } & \multicolumn{1}{c}{ Total } \\
\hline $\begin{array}{l}\text { Biaya }(\text { Total } \\
\text { Biaya } / \mathrm{kg})\end{array}$ & $7.420,68$ & $6.358,61$ & $13.779,29$ \\
$\%$ Biaya $/ \mathrm{kg}$ & 53,85 & 46,15 & 100 \\
Revenue $(\mathrm{Rp} / \mathrm{kg})$ & 19.450 & 48.000 & \\
Laba $(\mathrm{Laba} / \mathrm{kg})$ & $12.029,32$ & $41.641,39$ & $53.670,71$ \\
$\%$ laba Total & 22,25 & 77,75 & 100 \\
$\begin{array}{l}\text { Total Margin } \\
\text { (Margin } / \mathrm{kg})\end{array}$ & 19.450 & 28.550 & 48.000 \\
$\%$ Margin/kg & 40,52 & 59,48 & 100 \\
\hline
\end{tabular}

Tabel 5. Selisih Pendapatan Petani Parika Bermitra dan Tidak Bermitra Per Musim Tanam

\begin{tabular}{rrrr}
\hline No & $\begin{array}{r}\text { Income Non } \\
\text { Kemitraan }\end{array}$ & $\begin{array}{r}\text { Income } \\
\text { Kemitraan }\end{array}$ & Selisih (Rp) \\
\hline 1 & 14.727 .000 & 92.122 .500 & 77.395 .500 \\
2 & 42.474 .000 & 116.562 .00 & 74.088 .000 \\
3 & 11.126 .400 & 59.349 .750 & 48.223 .350 \\
4 & 13.826 .400 & 63.835 .800 & 50.009 .400 \\
5 & 29.311 .500 & 82.893 .000 & 53.581 .500 \\
6 & 53.536 .500 & 146.164 .500 & 92.610 .000 \\
7 & 3.985 .000 & 28.791 .250 & 24.806 .250 \\
8 & 11.936 .500 & 76.432 .750 & 64.496 .250 \\
9 & 38.474 .000 & 109.916 .000 & 71.442 .000 \\
10 & 8.485 .000 & 36.268 .000 & 27.783 .000 \\
\hline
\end{tabular}

Tabel di atas menjelaskan bahwa ratarata pendapatan petani mengalami peningkatan setelah melakukan kemitraan dengan Kostaman Fruit And Vegetables Supplier, berdasarkan 
perhitungan biaya produksi, penerimaan dan pendapatan terlihat pendapatan petani paprika meningkat mencapai dua kali lipat dari pendapatan sebelum melakukan kemitraan. Selisih pendapatan diperolah dari pendapatan yang bermitra dengan Kostaman Fruit And Vegetables Supplier dan menjual produknya ke pasar tradisional dengan petani yang hanya menjual paprika ke pasar tradisional tanpa melakukan kemitraan dengan Kostaman Fruit And Vegetables Supplier.

Selisih ini dikarena ada perbedaan harga jual paprika, Kostaman Fruit And Vegetables Supplier pemberikan harga yang lebih tinggi dibandingkan dengan di pasar tradisional. Harga jual paprika hijau Rp 17.000, paprika merah Rp 22.000, paprika kuning Rp 25.000 dan Rp 27.000 untuk paprika orange, sedangkan harga jual parika di pasar tradisional hanya Rp 10.000 - Rp 12000 untuk setiap jenis paprika.

Peningkatan pendapatan juga dikarenakan adanya peningkatan produksi karena kemampuan petani dalam melakukan usahatani menjadi meningkat. Petani mampu membeli kebutuhan usahataninya karena adanya harga dan pasar yang jelas setelah melakukan kemitraan. Kemitraan yang terjadi sangat menguntungkan baik bagi petani maupun Kostaman Fruit And Vegetables Supplier ini dibuktikan dengan peningkatan produksi, adanya jaminan pasar, harga jual yang tinggi dan bagi Kostaman Fruit And Vegetables Supplier tersedianya pasokan paprika sesuai dengan kualitas, kuantitas dan kontinuitas sehingga proses kemitraan ini dapat terus berlanjut.

\section{KESIMPULAN}

Mekanisme kemitraan usaha antara petani paprika desa Cibodas Kecamatan lembang Kabupaten Bandung Barat dengan Kostaman Fruits and Vegetables Suppliers adalah petani paprika berada pada subsistem kegiatan produksi dalam usahatani paprika sedangkan Kostaman Fruits and Vegetables Suppliers pada subsistem pemasaran hasil. Kostaman Fruits and Vegetables Suppliers menerima paprika yang dihasilkan petani sesuai dengan kualitas, kuantitas dan kontinuitas. Harga jual paprika adalah Rp 17.000 untuk paprika hijau, Rp 22.000 untuk paprika merah, Rp 25.000 untuk paprika kuning dan Rp 27.000 untuk paprika orange.
Kendala yang dihadapi dalam proses kemitraan antara petani paprika dengan Kostaman Fruits and Vegetables Suppliers adalah kendala teknis (kualitas dan kuantitas) karena kondisi cuaca yang tidak stabil. Manfaat yang diperoleh dari proses kemitraan adalah kepastian harga dan pasar, penerimaan dan pendapatan petani yang relatif stabil sedangkan bagi Kostaman Fruits and Vegetables Suppliers tersedianya pasokan paprika sesuai dengan kualitas, kuantitas dan kontinuitas yang dibutuhkan perusahaan. Peningkatan pendapatan petani paprika dilihat dari margin yang diterima petani sebesar 40,52\% dan margin yang diterima Kostaman Fruits and Vegetables Suppliers sebesar 59,48 \%.

\section{DAFTAR PUSTAKA}

Cahyono D. 2017. Cabai Paprika Teknik Budidaya dan Analisis Usahatani. Yogyakarta. Kanisius

Haeruman, Herman. 2001. Kemitraan dalam Pengembangan Ekonomi Lokal: Bunga Rampai. Jakarta: Yayasan Mitra Pembangunan Desa-Kota.

M4P.2012. Membuat Rantai Nilai Lebih Berpihak Pada Kaum Miskin : Buku pegangan bagi Praktiisi analisis rantai nilai. ACIAR Monogragraph No. 148. Australian Centre For International Agriculture Research : Canbera

Porter M. E. 1985. Competitive Advantages : Creating and Sustaining Superior Perfomance. New York: The Free Press.

Prowse, Martin. 2012. Contract Farming in Developing Countries. Institute of Development Policy and Managemet. University of Antwerp.

Rodjak, Abdul. 2005. Manajemen Usahatani. Penerbit : Giratuna. Bandung.

Saptana, dkk. 2006. Analisis Kelembagaan Kemitraan Rantai Pasok Komoditas Hortikultura. Bogor : Pusat Analisis Sosial Ekonomi dan Kebijakan Pertanian, Badan Litbang Pertanian, Departemen Pertanian.

Sumardjo, Jaka S., dan Wahyu A.D. 2004. Teori dan Praktik Kemitraan Agribisnis. Jakarta : Penebar Swadaya. 